\begin{tabular}{|c|c|c|}
\hline & $\begin{array}{c}\text { Gazi University } \\
\text { Journal of Science }\end{array}$ & 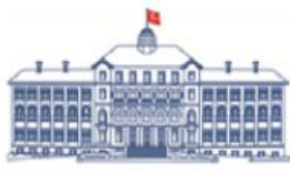 \\
\hline & http://dergipark.gov.tr/gujs & \\
\hline
\end{tabular}

\title{
Implementation of Adaptive Neuro Fuzzy Controller for Fuel Cell Based Electric Vehicles
}

\author{
K. Harshavardhana REDDY ${ }^{1, *}$, Sachin SHARMA ${ }^{1}$ (D) , K. Shivarama KRISHNA ${ }^{2}$ (D) \\ ${ }^{I}$ Department of ECE, East Point College of Engineering \& Technology, Bengaluru, India \\ ${ }^{2}$ Department of EEE, J.B Insitute of Engineering \& Technology, Hyderabad, India
}

\author{
Highlights \\ - Designed the Adaptive Neuro Fuzzy system based soft computing controller. \\ - The Proposed method is implemented to control speed in EV's. \\ - The ANFIS based soft computing technique is compared with various existing methods.
}

\begin{tabular}{l} 
Article Info \\
\hline $\begin{array}{l}\text { Received: } 03 / 03 / 2020 \\
\text { Accepted: } 11 / 06 / 2020\end{array}$ \\
Keywords \\
\hline Electric vehicle \\
BLDC motor \\
Speed control \\
Fuzzy PID controller \\
ANFIS controller
\end{tabular}

\begin{abstract}
The global concern for clean energy generation paved the way for technological inventions and provided scope for researchers. More prominently, integration of heterogeneous renewable sources, storage systems, and electric vehicles became the pioneer solutions. In this article, a soft computing based ANFIS method has been proposed to execute the rapid speed response in electric vehicle. Here, Brushless DC motor was used as a propulsion system to drive the vehicle. Electric Vehicle is basically a time variant system, whose operating parameters and road conditions vary continuously. To address these uncertainties, a novel control strategy is proposed. The fuel cell battery is used as the auxiliary power supply for the electric vehicle. To demonstrate the performance of the controllers, a case study has been considered with parameter uncertainties for an ECE-15 test cycle. To evaluate the proficiency of the proposed soft computing control method, the speed response results are evaluated and compared with existing methods like conventional PI and fuzzy based tuned PID controllers. In addition, the performance of proposed technique is benchmarked with other controllers reported in the literature.
\end{abstract}

\section{INTRODUCTION}

In Now days, saving of electric energy has attracted a lot of researchers due to continuous exhaustion of fossil elements and rapid rise in greenhouse gas emissions. Because of this, there is growing interest among researchers to concentrate on technologies related to energy savings [1]. Taking this into account, the automobile industry has focused on alternative energy sources other than petrol or diesel for fueling vehicles which resulted in the usage of electric vehicles. Therefore, the development of Electric Vehicles (EVs) is taking a quick pace in marketing.

The EVs have certain advantages like low weight, low CO2 emissions, easy cooling, excellent speed-torque characteristics, low protection cost, high reliability, simple drive train systems and high-energy conversion efficiency. Configuration of EVs is more flexible compared to Internal Combustion Engine Vehicles (ICEVs) [2]. Some of the applications are implementation in short-range transportations, motorized wheelchairs, and patrolling vehicles. In future EVs can be preferred for public transportations [3]. Generally, EVs consists of five parts: Electric motor, control system, batteries, bodywork, and charger. The performances of the EVs rely on three factors. They are energy source, vehicle expectation, and constraints [3-5]. In electric propulsion system Permanent Magnet (PM), brushless (BLDC) motors and induction motors are mostly used [6]. The Brush less DC motor is explained as synchronous motor have trapezoidal back EMF, which is used broadly in numerous applications like robotics, chemical industries, aeronautics, 
and electric vehicles. etc. Since they require no mechanical commutators, it would have certain amenities such as easier control, high power density, produce require torque and more efficiency [7].

In this paper, EVs, which consist of BLDC motors are considered for the study. In EVs, the controller plays a crucial role to obtain the maximum accelerated performance. Because EV's run on different road conditions and also the operating parameters always variable in nature $[8,9]$. Therefore, control of EV's become a key topic of research in the recent past [10]. Ziegler- Nichols [11] first implemented the PI/PID controller tuning. In process industries, chemical industries, and also various electrical control applications $\mathrm{PI} / \mathrm{PID}$ controllers are used because it is easy to design [12].

In [13] PID controller is applied to control an electric wheelchair. For nonlinear and complex systems of EVs, the PI/PID controllers do not give optimal performance. In [14] a hybrid PID controller applied for the nonlinear system is proposed. This hybrid controller is resulted by swapping the normal PI controller with two normalized fuzzy logic controller one for proportional gain and another one is for incremental gain where the derivative gain is accounted as incremental gain. In control applications like temperature process, industrial conveyor, and renewable applications these fuzzy logic controllers (FLCs) are used [1517]. The fuzzy logic controller is convenient to apply for electric vehicles [18] because EVs operate at complex conditions. To provide high starting torque for the EVs at higher efficiency and speed tracking, the fuzzy logic controller is implemented [19] using DSP embedded PID controller.

The authors in [20], have designed a robust and optimal controller to control motor in EV. A Linear Quadratic Regulator (LQR) and differential geometric approach has been implemented. In addition the robust controller gives better performance under uncertainties of EV operations. The demerit of the controller is that the selection of LQR weight matrixes is difficult. In [21] the authors have implemented a control for regenerative braking of EVs considering parametric variation and uncertainties using the robust $\mathrm{H}$ - controller. Recently, an electric vehicle using type 2 fuzzy PI controller and the T-S model predictive controller is proposed [22, 23]. In [24], PI and FLC are used to improve the engine power in hybrid electric vehicles. But this controller gives more settling time and overshoot.

A control technique called ANFIS controller is used in numerous applications such as maximum power extraction in solar panels and inertia control of wind turbines [25, 26], silicone rubber mechanical properties approximation [27], robotic gripper control [28], human musculoskeletal arm [29], anti-lock braking system [30], underwater vehicles [31], control of nonlinear industrial process and batch process [32, 33], estimation of system forecasting [34], estimation of open lens system parameters [35].

In $[36,37]$, ANFIS controller is used for speed control of permanent magnet excitation transverse flux linear motor and BLDC motor. This ANFIS gives satisfactory performance under load varying conditions. In [38], a fuzzy PID supervised ANFIS controller is proposed for BLDC type motors. The recursive least square back propagation algorithm is used to train the ANFIS system. In this work an ANFIS controller has been implemented for speed control of EVs. In this controller, the training data for the ANFIS is obtained from the performance of fuzzy PID controller. The proposed controller has certain advantage that it gives better performance in uncertain conditions also. The simulation results prove that the proposed method is superior to the PI and fuzzy PID controller. The structure of the paper is as follows, section 1 explains the introduction and literature survey, the design of $\mathrm{EV}$ is presented in section 2 and section 3 deals with the implementation of ANFIS controller for EV. In section 4 results and discussions are presented. In section 5 conclusion of work is described.

\section{EV SYSTEM MODEL}

The vehicle and motor dynamics are two significant parts of EVs model which is shown in Figure 1. 


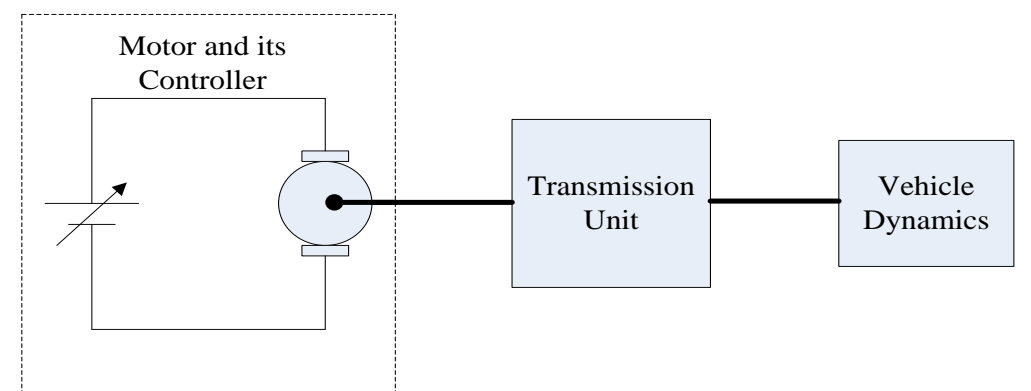

Figure 1. EV System Model

\subsection{Vehicle Dynamics}

A In the modeling of EVs dynamics, the factors considered to design road condition are hill climbing, acceleration and aerodynamic drag etc. After considering these parameters, the model is represented as shown in Equation (1) [39]

$$
F=\mu_{r r} m g+\frac{1}{2} \rho A C_{d} v^{2}+m g \sin \phi+m \frac{d v}{d t}
$$

where $g$ represents acceleration gravity, $v$ represents vehicle driving velocity, $\mu \_$rr represents coefficient of rolling resistance, $\rho$ represents air density, A represents frontal area, Cd the drag coefficient and $\varnothing$ is the hill climbing angle.

In Equation (1), the first, second, third and fourth term are given as rolling resistance force, aerodynamic drag force, hill climbing force and acceleration force respectively. The following equation shows the relationship between the force $\mathrm{F}$ that produced a counteractive torque to the driving motor which is given as in Equation (2)

$T_{L}=F \cdot \frac{r}{G}$

where $r$ represents radius of tyre in $(\mathrm{m})$ of the $\mathrm{EV}, \mathrm{G}$ indicates gearing ratio and $\mathrm{TL}$ represents torque in $(\mathrm{Nm})$ and $\mathrm{F}$ is total force.

\subsection{Motor Model}

The BLDC motor diagram is shown in the Figure 2. The equation for line to line voltage are given in Equation (3)

$$
\left[\begin{array}{l}
v_{a b} \\
v_{b c} \\
v_{c a}
\end{array}\right]=\left[\begin{array}{ccc}
R_{n} & -R_{n} & 0 \\
0 & R_{n} & -R_{n} \\
-R_{n} & 0 & R_{n}
\end{array}\right]\left[\begin{array}{l}
i_{a} \\
i_{b} \\
i_{c}
\end{array}\right]+\left[\begin{array}{ccc}
L_{n} & -L_{n} & 0 \\
0 & L_{n} & -L_{n} \\
-L_{n} & 0 & L_{n}
\end{array}\right]\left[\begin{array}{l}
\frac{d i_{a}}{d t} \\
\frac{d i_{b}}{d t} \\
\frac{d i_{c}}{d t}
\end{array}\right]+\left[\begin{array}{l}
e_{a}-e_{b} \\
e_{b}-e_{c} \\
e_{c}-e_{a}
\end{array}\right]
$$

where, $R_{n}$ is the resistance of stator Windings in ohms, $L_{n}$ and $M$ represents the Self Inductance and mutual inductance respectively and $e_{a}, e_{b}$ and $e_{c}$ are emf. $V_{a b c}$ represents the phase voltages, $i_{a b c}$ as phase currents. The number of poles in the rotor are given in $\mathrm{P}$.

The $\mathrm{T}_{\mathrm{e}}$ of the BLDC motor is shown in below Equation (4)

$$
T_{a}=\left(e_{a} i_{a}+e_{b} i_{b}+e_{c} i_{c}\right) / w_{l} ; w_{l}=\frac{d \theta_{r}}{d t}
$$

where, $\mathrm{w}_{1}, \theta_{r}$ represents the rotor position, angular velocity ( $\left.\mathrm{rad} / \mathrm{s}\right)$, respectively.

The $T_{e}$ is employed to subdue the opposing torques of load and inertia, it is given in Equation (5) 


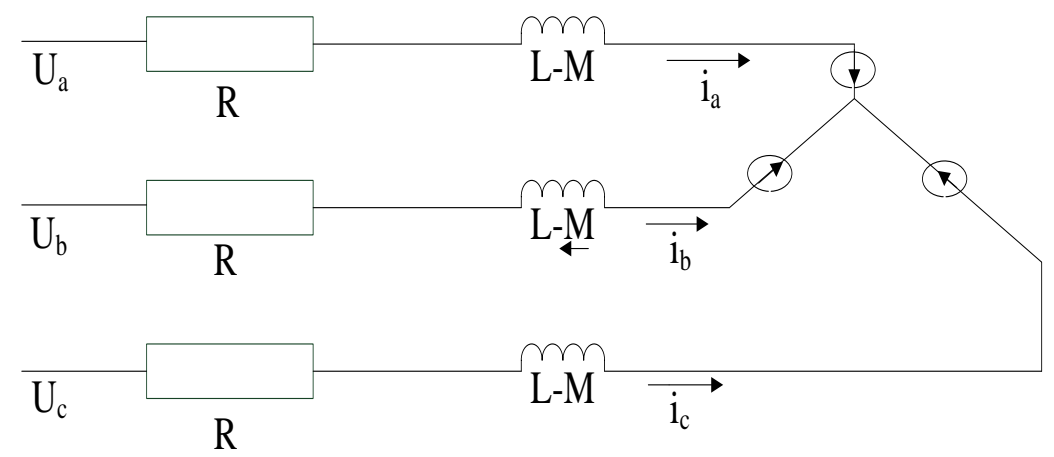

Figure 2. Stator winding of BLDC Motor

$T_{a}=T_{L}+J_{n} \frac{d w}{d t}+B_{n} w$

where $T_{L}$ represents load torque $(\mathrm{Nm}), \mathrm{J}_{\mathrm{n}}$ is Momentum of Inertia $\left(\mathrm{J}\right.$ or $\left.\mathrm{kg} / \mathrm{m}^{2}\right), B_{\mathrm{n}}$ indicates Friction coefficient.

The BLDC motor advantages, with respect to other motors are lower electromagnetic interference (EMI), lower maintenance costs and higher reliability $[39,40]$. Then the overall block diagram to simulate the electric vehicle is depicted in Figure 3. It comprises of a fuel cell battery to supply the power using DC-DC converter and inverter and the electric motor is connected to EV [41-45].

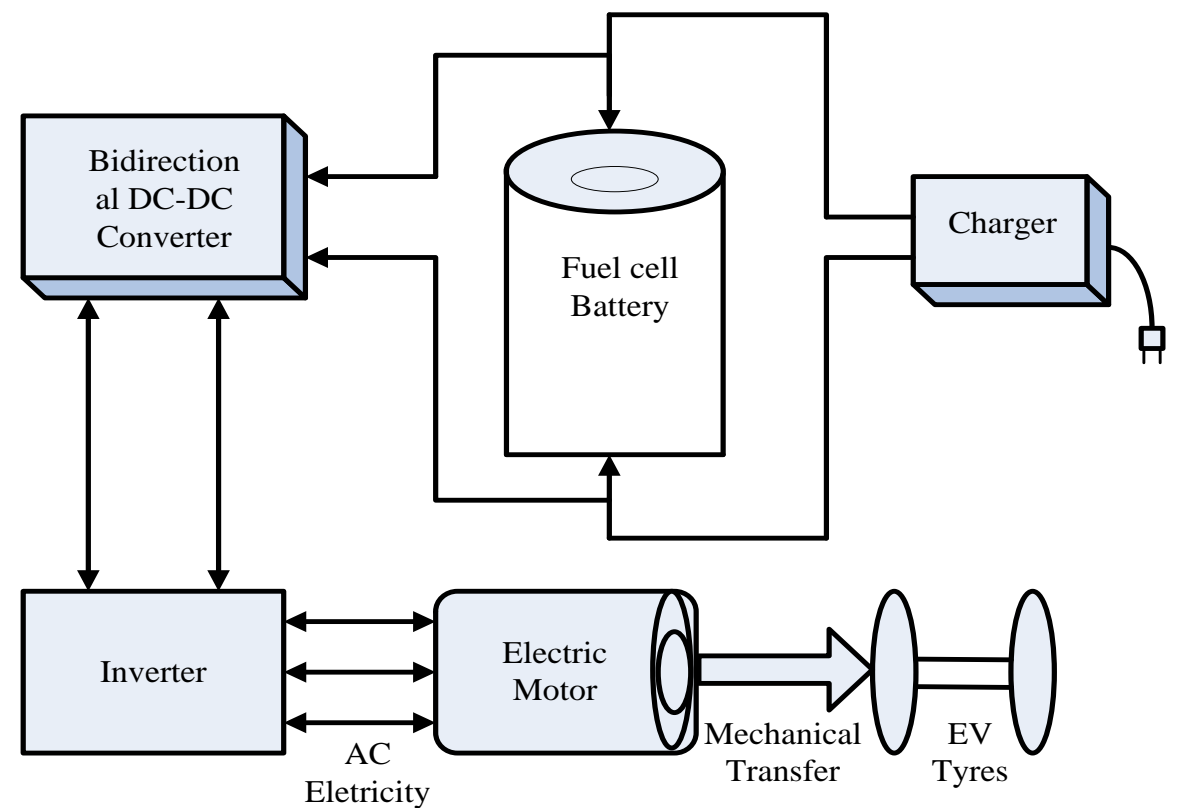

Figure 3. Block diagram representation of Electric Vehicle

The Figure 4 describes the speed control brushless DC motor using the adaptive neuro fuzzy interface system, Fuzzy PID and PI Controller. The above circuit has a closed loop system to control the speed of the BLDC motor, the speed of the BLDC motor controlled by the dc bus voltage through pulse width modulation based voltage inverter. The control signal and the switching logic is given to the three phase PWM volt age inverter, the feedback error signal generate through the output of the brushless DC motor and the reference speed of the BLDC motor is given to controller block. 


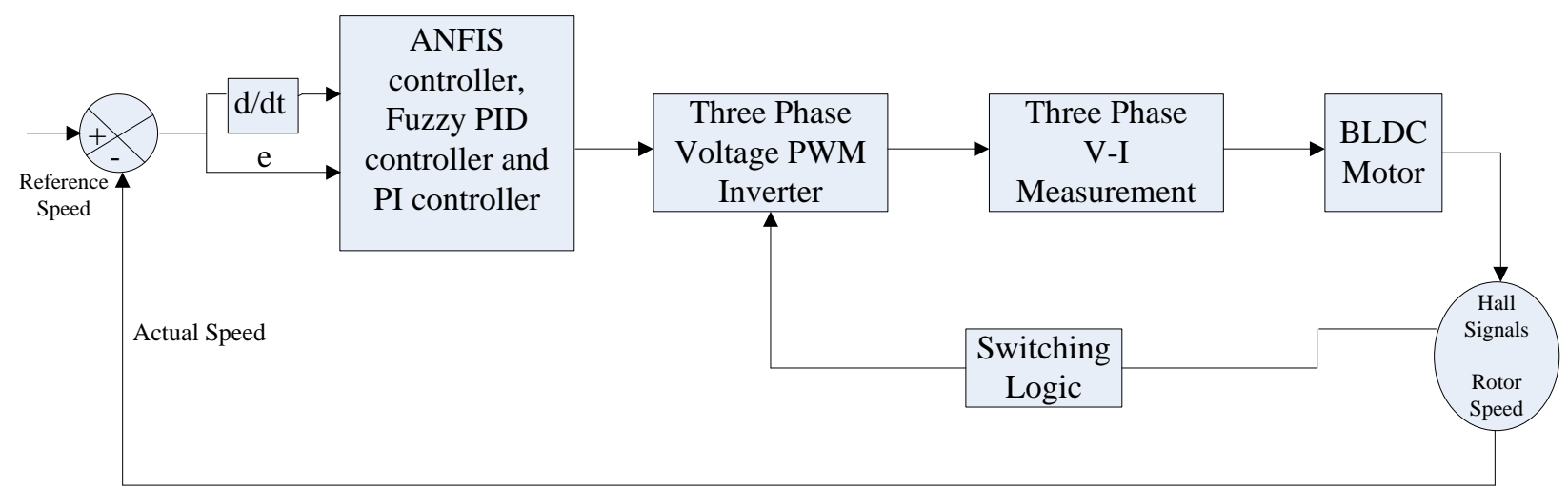

Figure 4. Simulation Model for Speed Controller of BLDC Motor in EVs

\section{SPEED CONTROL TECHNIQUES FOR ELECTRIC VEHICLES}

To control the speed of EV, ANFIS controller is proposed and in order to analyze the betterment of the proposed method it is compared with the conventional PI and Fuzzy PID controller.

\subsection{PI Controller Design}

There are two variables in PI Controller commonly known as proportional gain $\mathrm{K}_{\mathrm{p}}$ and integral gain $\mathrm{K}_{\mathrm{i}}$ for which the transfer function is given in Equation (6)

$$
X(s)=k_{p}+\frac{k_{i}}{s} \text {. }
$$

In order to design the PI controller in Electric Vehicle System with control on speed, the two controller gains are considered as state variables. which are stated in Equation (7)

$$
u(t)=k_{p} x(t)+k_{i} \int x(t) d t .
$$

The Tuning of proponational gain and Integral gain of PI Controller is governed by the Ziegler- Nichols method.[11]. So for the speed control in EV system the obtained $\mathrm{k}_{\mathrm{p}}$ is 0.013 and Integral gain $\mathrm{k}_{\mathrm{i}}$ is 12 .

\subsection{Fuzzy PID Controller design}

Rate of change of error and error are the two inputs for the fuzzy interface system for which the block diagram is demonstrated in Figure 5. Outputs and inputs both have seven trigonal membership functions and the input ranges between [-0.5 to 0.5] for both input and output. The distribution of the members has seven functions smal lpositive, medium positive and big positive,zero, big negative, medium negative, negative small. The membership functions distribution is as shown in the Figure 6.

Centroid method gives defuzzification of these fuzzy sets which is also called as the area centric or gravity cetric. The defuzzification formula is stated in Equation (8)

$x=\int V_{c}(x) \cdot z d z / \int V_{c}(x) d x$.

For the tuning of the fuzzy based PID forty nine rules are used, and some of the examples of these rules are as given below.

Output is big negative if change in error is big negative and error is zero.

Output is medium negative if change in error is medium negative and error is zero.

Output is small negative if change in error is small negative and error is zero. 
Where the integration represents the Algebraic integration of the membership functions. The gains used for the BLDC motor to tune fuzzy PID controller is $\alpha, \beta$. The values of $\alpha$ and $\beta$ is 0.00169 and 48 respectively. Integrator gain is approximated as 48 and derivative gain as 0.8 .

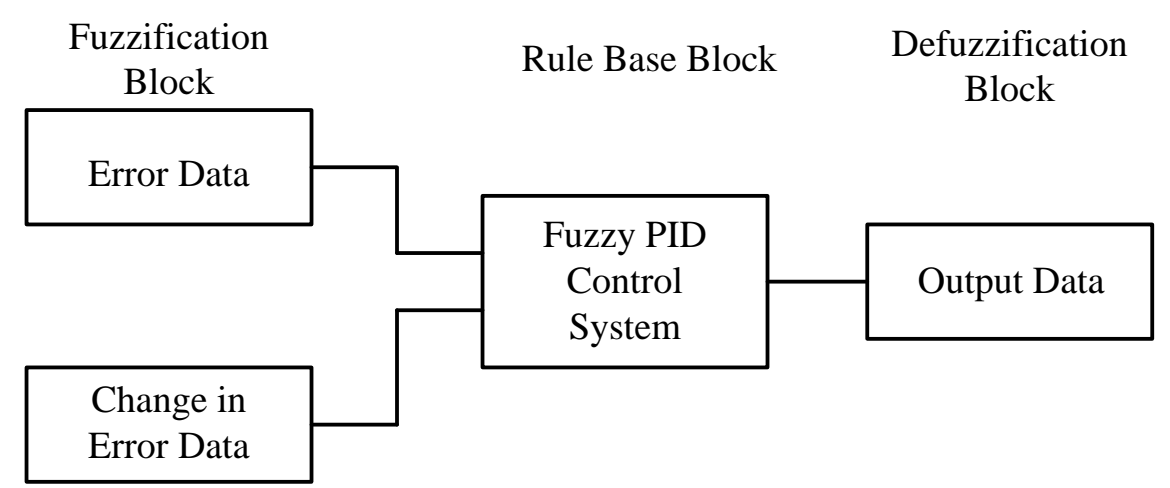

Figure 5. Mamdani FIS

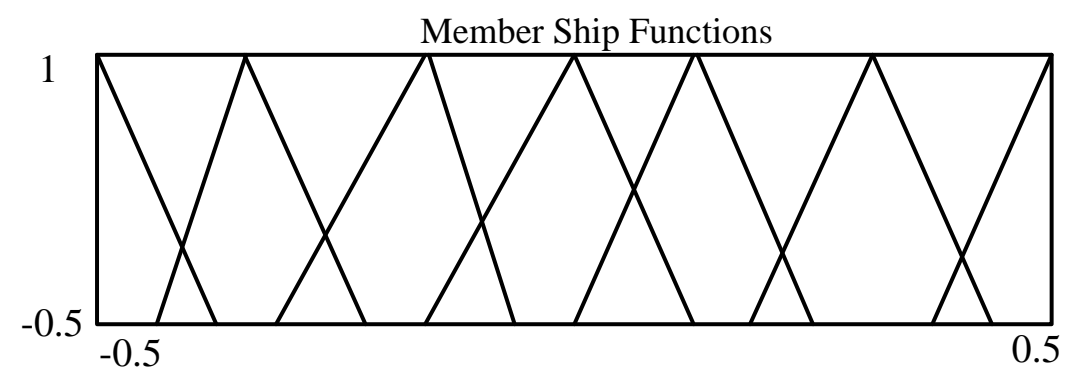

Figure 6. Membership functions of inputs and outputs for proposed controller

\subsection{Adaptive Neuro Fuzzy Controller}

It is mixture of ANN with fuzzy interface system. The Takagi - Sugeno model is used in this proposed work [46]. ANFIS is a very good learning technique to take over an issue on uncertainties in any system. This controller is based on framing fuzzy IF-Then rules that produces specific input-output with the help of membership functions. The learning process of ANFIS consists of three stages; first is the rule base, second is the membership functions and the third is the reasoning mechanism [35, 39].

Consider the set of fuzzy rules;

Let $R_{j}=$ If $x_{1}$ is $A_{1}\left(x_{1}\right)$ and $x_{2}$ is $A_{2 j}\left(x_{2}\right)$ and ........ $x_{n}$ is $A_{n j}\left(x_{n}\right)$ THEN $y$ is $c_{j}$

where,

$\mathrm{x}_{1}=$ change in error given as $\mathrm{w}_{\text {ref }^{-}} \mathrm{W}_{\mathrm{r}}$.

$\mathrm{X}_{2}=$ derivative of change in error given as $\mathrm{d}\left(\mathrm{w}_{\text {ref- }}-\mathrm{w}_{\mathrm{r}}\right) / \mathrm{dt}$.

$\mathrm{y}=$ output given as $\mathrm{P}_{\mathrm{ix} 1}+\mathrm{R}_{\mathrm{ix} 2}+\mathrm{S}_{\mathrm{i}}$

$\mathrm{A}_{1}\left(\mathrm{x}_{1}\right)$ and $\mathrm{A}_{\mathrm{nj}}\left(\mathrm{x}_{\mathrm{n}}\right) \ldots \ldots \ldots \mathrm{A}_{\mathrm{nj}}\left(\mathrm{x}_{\mathrm{n}}\right)$ are input linguistic labels and $\mathrm{c}_{\mathrm{j}}$ is constant consequent labels.

In TS Fuzzy model, to find the conclusion for input $\mathrm{X}$ an inference procedure is implemented, which is listed in two steps as given below.

The weight of $\mathrm{w}_{\mathrm{j}}$ in each rule is calculated as shown in Equation (9)

$w_{j}=\prod_{i=1}^{n} \mu_{i j}\left(x_{i}^{0}\right)$

where $\mathrm{w}_{\mathrm{j}}$ is weights of each rule, $\mu_{\mathrm{ij}}$ is linguistic label. 
The output inference result y is obtained by means of the weighted average of the consequents in Equation (10)

$$
y=\frac{\sum_{j=1}^{m} w_{j} c_{j}}{\sum_{j=1}^{m} w_{j}}
$$

where, $y$ is output, $w_{j}$ is weights, and $c_{j}$ is constant consequent labels.

Equations (9) and (10) provides the complete representation of the inference model.

The Architecture of ANFIS network consists of different types of inference models as adaptive networks. The adaptive network consists of following layers as shown in Figure 7. The layer 1 having $\mathrm{m}$ groups and having $\mathrm{n}$ nodes of each one.

Every single node generates output by solving each membership function as shown in Equation (11)

$k_{i j}^{(1)}=\mu_{i j}\left(x_{i}^{0}\right)=f\left(x_{i}^{0} ; p_{1 i j}, p_{2 j} \ldots ..\right)$

where $\mathrm{k}_{\mathrm{ij}}$ is the outputs of the nodes.

The $2^{\text {nd }}$ layer represents the precondition of the fuzzy rule and is denoted by ' $\pi$ ' which is multiplied with the signals to get output as shown in Equation (12)

$k_{j}^{(2)}=\prod_{i=1}^{n} k_{i j}^{(1)}=w_{j}$.

The layer 3 consists of an $\mathrm{m}$ - nodes normalization layer. The output of the $\mathrm{j}^{\mathrm{th}}$ node $k_{j}^{(4)}$ is the ratio of the $\mathrm{j}^{\text {th }}$ rules of weight to the sum of all the rules as Equation (13)

$k_{j}^{(4)}=\sum_{j=1}^{m} k_{j}^{(3)} c_{j}=y$.

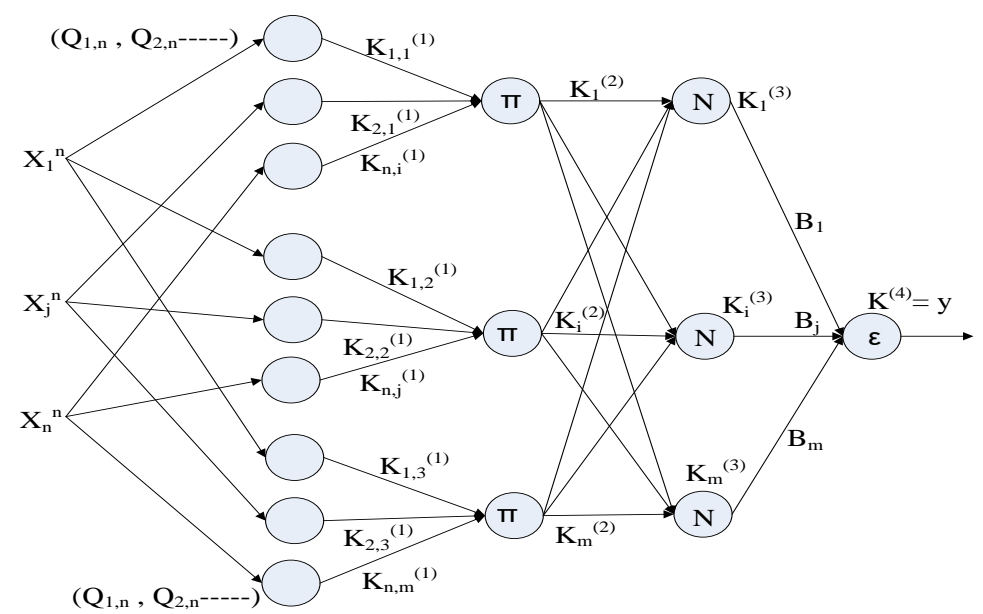

Figure 7. Architecture of an $n$ - input adaptive neuro fuzzy controller [39]

For the proposed controller the data of error and change in error of fuzzy PID plus PD controller data set is used. The structure of adaptive fuzzy controller, generated by the MATLAB code is a five layer network as shown in Figure 8. 
It has two inputs (error and change in error), one output and three membership functions.

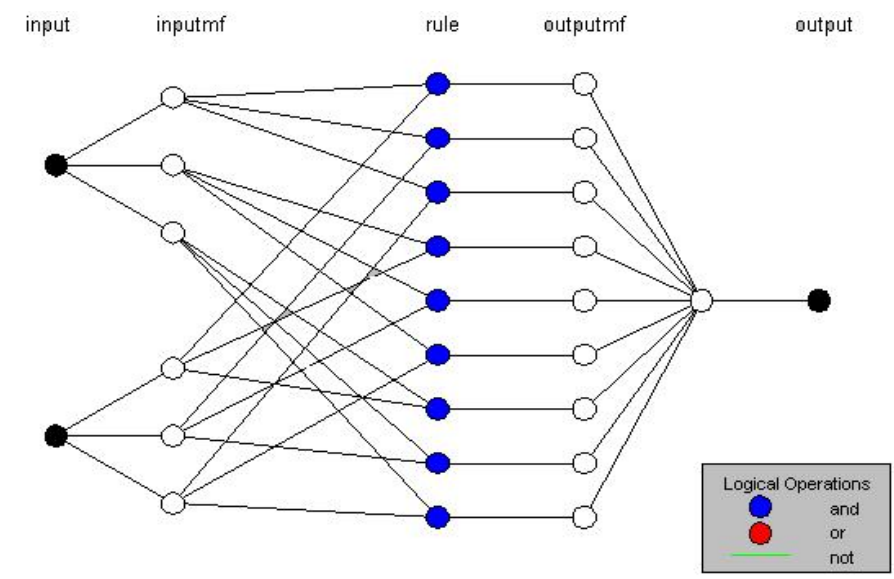

Figure 8. Structure for ANFIS controller [39]

The Figure 9 shows the output of fuzzy rule for a specific value of change in error and error.

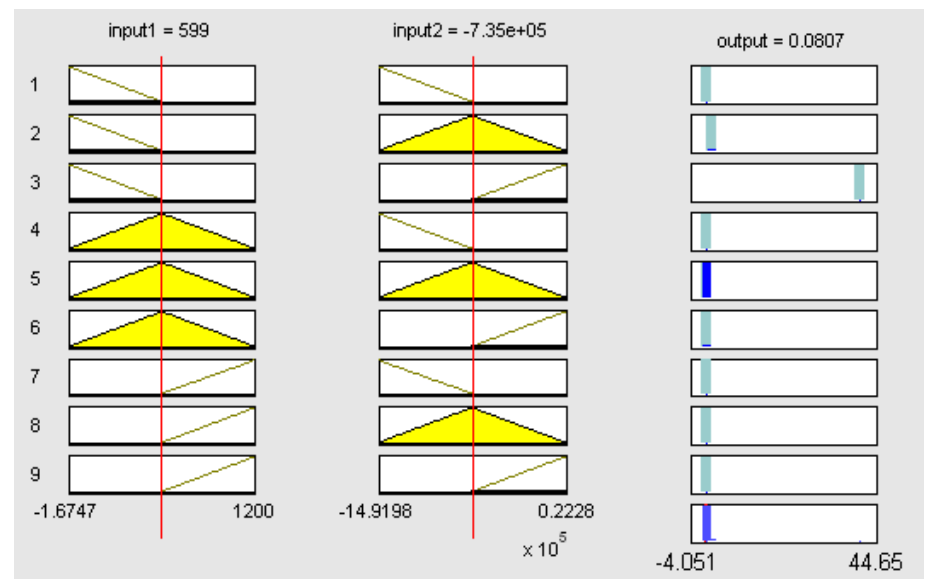

Figure 9. ANFIS Controller Rules

\section{SIMULATION RESULTS}

The proposed controller performance for the EV is studied and its efficiency is evaluated based on the obtained results that are compared with conventional controller. The Vehicle parameters are taken from [20] and are listed in Table 1.

\subsection{Case 1}

Case 1 deals with the performance of the controllers at constant speed when operating at $25 \mathrm{Km} / \mathrm{h}$. The proposed controllerand its performance is compared with existing controllers illustrated in Figure 10. It is realized that the proposed control method achieves enhanced response in shorter time. The control signal of control method is in Figure 11, from this it can be observed that the proposed control method based ANFIS has achieved enhanced performance using less control energy.

\subsection{Case 2}

In case 2, an ECE 15 cycle is used to validate the speed control of EVs for the proposed controller. The ECE 15 cycle profile obtained for a speed of $50 \mathrm{~km} / \mathrm{h}$ is shown in Figure 12. 
Table 1. Electric Vehicle Parameters

\begin{tabular}{|l|l|}
\hline \multicolumn{2}{|c|}{ Vehicle Parameters } \\
\hline Mass $(\mathrm{kg})$ & 800 \\
\hline Area $\left(\mathrm{m}^{2}\right)$ & 1.8 \\
\hline Air density $\left(\mathrm{kg} / \mathrm{m}^{3}\right)$ & 1.25 \\
\hline Drag Value & 0.3 \\
\hline Hill Climbing Angle $\left({ }^{0}\right)$ & 0 \\
\hline Rolling Resistance & 0.015 \\
\hline Tyre Radius $(\mathrm{m})$ & 0.025 \\
\hline Gearing Ratio & 11 \\
\hline
\end{tabular}

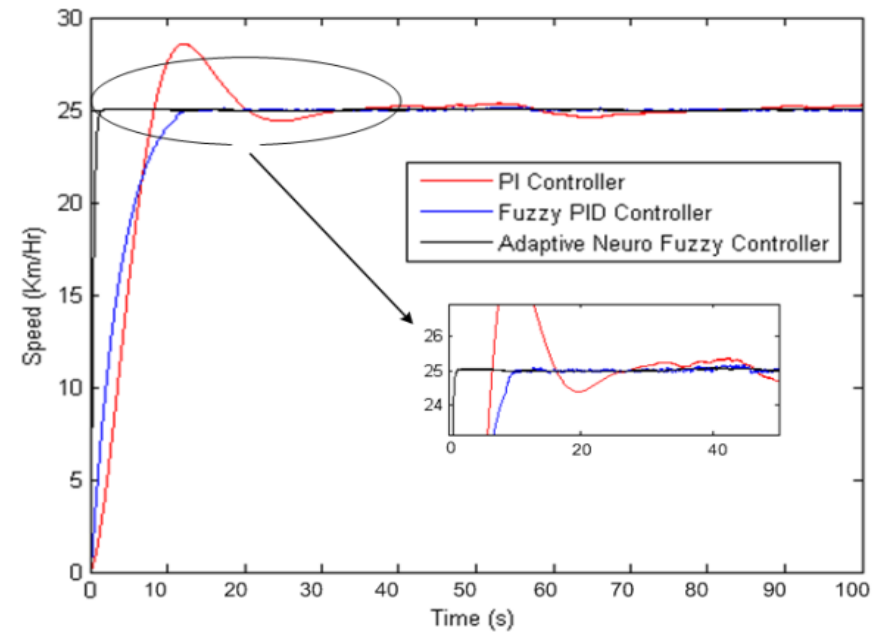

Figure 10. Performance of Controllers at constant $25 \mathrm{~km} / \mathrm{h}$ speed

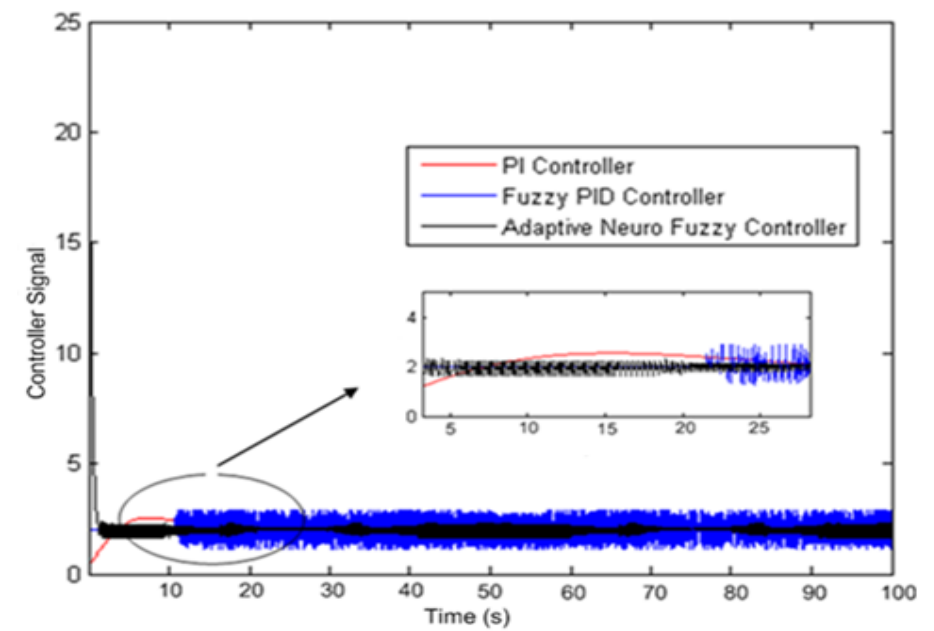

Figure 11. Control Error Signal for controller at constant $25 \mathrm{~km} / \mathrm{h}$ speed.

The performance of controller for ECE15 cycle profile is illustrated in Figure 13 and from the results it is realized that the tracking performance of proposed controller is better than the PI and Fuzzy PID controller for ECE 15 cycles. Figure 14 shows the control signal generated by the controllers for performing ECE 15 speed test. Figure 15 shows the same performace of controller for ECE test cycle with large time 400 seconds. For large time based ECE Test cycle also ANFIS controller will gives the good response.

The Integral Absolute Error (IAE) Settling time, Integral Square Error (ISE) and of proposed controller is compared with the available control techniques in literature and the same is presented in Table 2. 


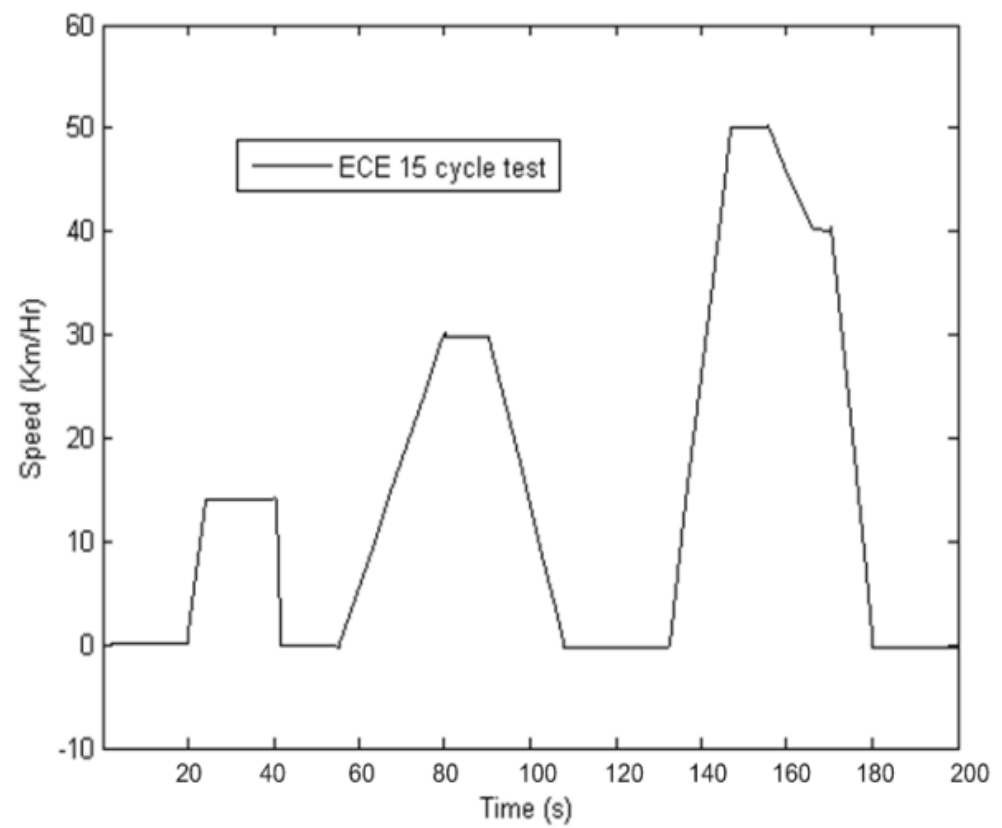

Figure 12. ECE 15 Cycle Test

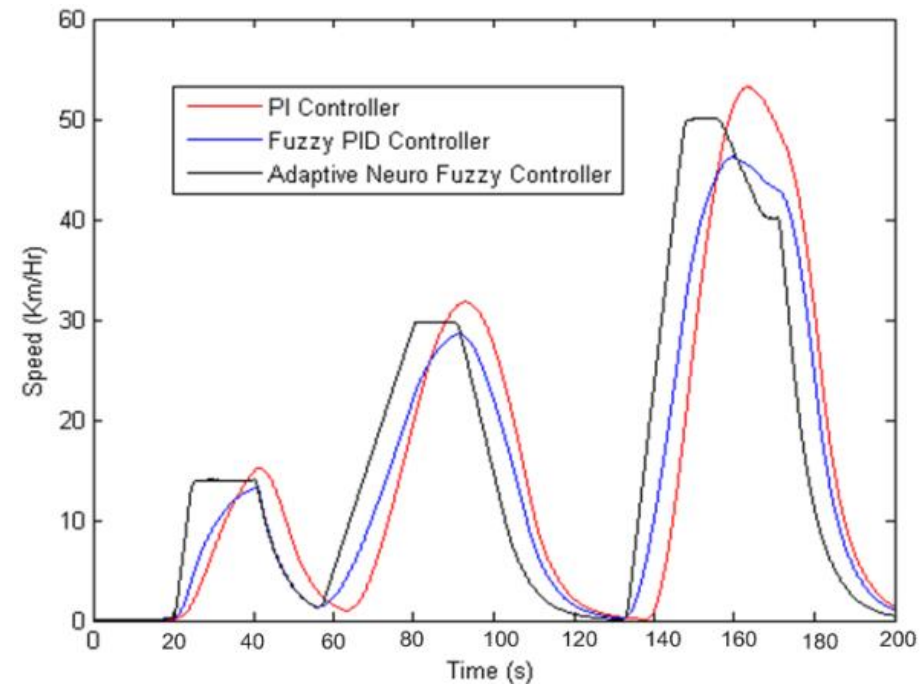

Figure 13. Performance of controller for ECE15 cycle test

As we observe in Table 2 the existing PI controller, Fuzzy logic controller and Type-2 Fuzzy logic controllers settle at 25,10 and $2 \mathrm{sec}$ respectively and the proposed controller settles at $0.5 \mathrm{sec}$. As observed in the Table 2 ISE and IAE also has low values for proposed technique. Hence it can be concluded that stable output speed can be obtained from the proposed controller. 


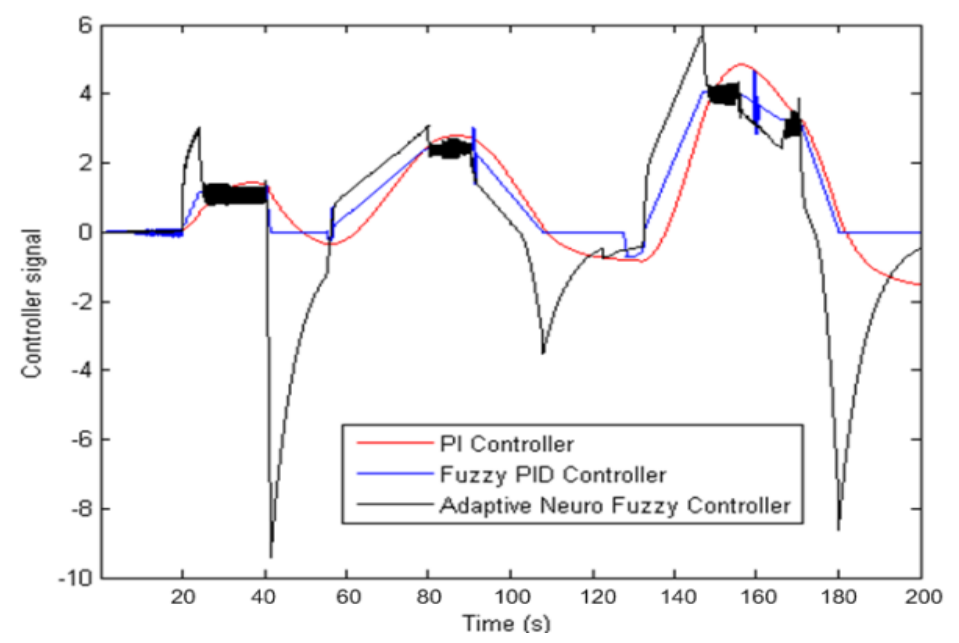

Figure 14. Control error signal of controllers for ECE 15 cycle test

Table 2. Comparison table for performace of diffrent Controllers

\begin{tabular}{|l|l|c|l|l|}
\hline Sl.no. & Controllers & Settling Time (Sec) & ISE & IAE \\
\hline 1 & PI controller [24] & 25 & 3564 & 9.189 \\
\hline 2 & Fuzzy Logic Controller[24] & 10 & 3154 & 9.178 \\
\hline 3 & $\begin{array}{l}\text { PI Controller - Type- } \\
\text { Fuzzy logic [22] }\end{array}$ & 2 & 2978 & 8.828 \\
\hline 4 & Proposed Controller & 0.5 & 2842 & 7.68 \\
\hline
\end{tabular}

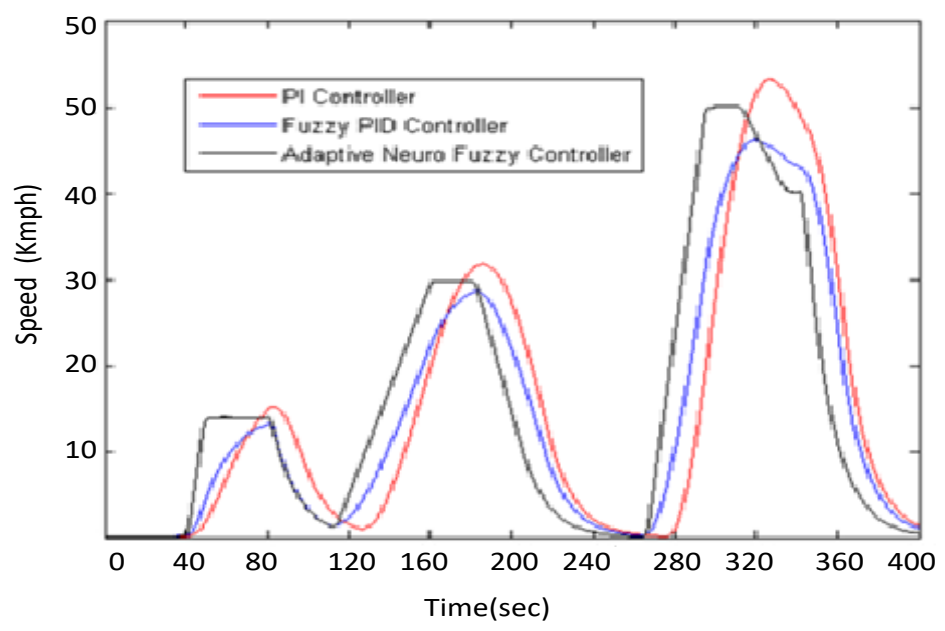

Figure 15. Peformane of controllers for ECE 15 cycle test with 400sec

\section{CONCLUSION}

In this work, an ANFIS is proposed for application of speed control in Electric Vehicles. The proposed method is evaluated on various EVs under different conditions. The implementation of proposed control strategy is easy and unsophisticated. To evaluate the robustness of the proposed method comparison has been made with the conventional PI and fuzzy PID controllers. The proposed control strategy gives good speed tracking performance than other controllers. The ECE 15 speed profile is used to validate the controller. The presented controller is also validated under various operating conditions and it is decided that it gives better task. 


\section{CONFLICTS OF INTEREST}

No conflict of interest was declared by the authors.

\section{REFERENCES}

[1] Chan, C.C., "The state of the art of electric and hybrid vehicles", Proc. IEEE, 90(2): 247-275, (2002).

[2] Leduc, P., Dubar, B., "Downsizing of gasoline engine: an efficient way to reduce CO2 emissions". Oil Gas Science Technology, 58: 115-27, (2003).

[3] Yang, Z., Shang, F., Brown, I. P., \& Krishnamurthy, M., "Comparative study of interior permanent magnet, induction, and switched reluctance motor drives for EV and HEV applications". IEEE Transactions on Transportation Electrification, 1(3): 245-254, (2015).

[4] Kim, K. C., "A novel magnetic flux weakening method of permanent magnet synchronous motor for electric vehicles", IEEE Transactions on Magnetics, 48(11): 4042-4045.

[5] Chan, C. C., Chau, K. T., Jiang, J. Z., Xia, W. A. X. W., Zhu, M., Zhang, R., "Novel permanent magnet motor drives for electric vehicles", IEEE Transactions on Industrial Electronics, 43(2): 331-339, (1996).

[6] Wang, J., Atallah, K., Zhu, Z. Q., Howe, D., "Modular 3-phase permanent magnet brushless machines for in-wheel applications", IEEE Vehicle Power and Propulsion Conference,1-6, (2006).

[7] Konstantinos, L.,I., Kladas A.,G., "Internal permanent magnet motor design for electric vehicle drive", IEEE Transactions on Industrial Electronics, 57(1): 138-145,(2010).

[8] Mura, R., Vadim, U., Simona, O., "Energy management design in hybrid electric vehicles: A novel optimality and stability framework", IEEE Transactions on Control Systems Technology, 23(4): 13071322, (2015).

[9] Overington, S., Sumedha, R., "High-efficiency control of internal combustion engines in blended charge depletion/charge sustenance strategies for plug-in hybrid electric vehicles", IEEE Transactions on Vehicular Technology, 64(1): 48-64, (2015).

[10] Sharma, I., Shubhi, P., "Nonlinear controllers for a light-weigted all-electric vehicle using Chebyshev neural network", International Journal of Veicular Technology, (2014)

[11] Ziegler, I. G., Nicholas, N B., "Optimum settings for automatic controllers". Trans. ASME, 64(11), (1942).

[12] Ramanathan, P., Arjun A, Mampilly., K.J, Marimuthu R. Ramasamy S., "Study and comparison of fuzzy logic and PI controller based on pressure control system", International Review on Modeling and Simulations, 5: 1356-1359,(2012).

[13] Brown, K., E., Rafael, Inigo R.,M., Johnson,B.W., "Design, implementation, and testing of an adaptable optimal controller for an electric wheelchair", IEEE Transactions on Industry Applications, 26 (6): 1144-1157,(1990).

[14] Er, M. J., Sun, Y. L., "Hybrid fuzzy proportional-integral plus conventional derivative control of linear and nonlinear systems". IEEE Transactions on Industrial Electronics, 48(6),1109-1117, (2001).

[15] Kasa, S., Ramasamy, S., Ramanathan, P., "Hybrid fuzzy-ZN PID control based grid interfaced distribution level renewable energy source with power quality", International Conference on Circuits, Power and Computing Technologie, 1-7, (2015). 
[16] Ramanathan, P., Sukanya, K. C., Mishra, S., Ramasamy., "Study on Fuzzy Logic and PID Controller for temperature regulation of a system with time delay", International Conference on Energy Efficient Technologies for Sustainability, 274-277, (2013).

[17] Srikar, S., B., Sarath K., M., Ramasamy, S., "Design and Implementation of fuzzy logic control based speed control of Industrial conveyor", ARPN Journal of Engineering and Applied Sciences, 9.(9): 1547-1553, (2014).

[18] Schouten, N. J., Salman, M. A., Kheir, N. A., "Fuzzy logic control for parallel hybrid vehicles", IEEE Transactions on Control Systems Technology, 10(3): 460-468, (2002).

[19] Wu, H. X., Cheng, S. K., Cui, S. M, “A controller of brushless DC motor for electric vehicle”, IEEE Transactions on Magnetics, 41(1): 509-513, (2005).

[20] Huang, Q., Huang, Z., Zhou, H., "Nonlinear optimal and robust speed control for a light-weighted allelectric vehicle",IET Control Theory \& Applications, 3(4): 437-444, (2009).

[21] Ye, M., Bai, Z., Cao, B., "Robust control for regenerative braking of battery electric vehicle". IET Control Theory \& Applications, 2(12): 1105-1114, (2008).

[22] Khooban, M., H., Taher,N., Mokhtar S., "Speed control of electrical vehicles: A Time-Varying Proportional-Integral Controller-based Type-2 Fuzzy Logic", IET Science, Measurement \& Technology, 10(3): 185-192,(2016).

[23] Khooban, M., H., Navid,V., Taher,N., "T-S fuzzy model predictive speed control of electrical vehicles", ISA Transactions,(2016).

[24] Syed, F., U., Kuang, M.L., Smith,M., Okubo,S., Ying,H., "Fuzzy gain-scheduling proportionalintegral control for improving engine power and speed behavior in a hybrid electric vehicle", IEEE Transactions on Vehicular Technology, 58(1): 69-84,(2009).

[25] Petković, D., P., Cojbasic, Z., Nikolic.V.,Shamsirband,S., Kiah, M.L.M., Anur,N.B., Wahab, A.W.A., "Adaptive neuro-fuzzy maximal power extraction of wind turbine with continuously variable Transmission" Energy, 64: 868-874,(2014).

[26] Hafiz, F., Abdennour, A., "An adaptive neuro-fuzzy inertia controller for variable-speed wind turbines". Renewable Energy, 92: 136-146, (2016).

[27] Petković, D., Issa, M., Pavlović, N. D., Pavlović, N. T., Zentner, L., “Adaptive neuro-fuzzy estimation of conductive silicone rubber mechanical properties". Expert Systems with Applications, 39(10): 9477-9482, (2012).

[28] Petković, D., Issa, M., Pavlović, N. D., Zentner, L., Ćojbašić, Ž., “Adaptive neuro fuzzy controller for adaptive compliant robotic gripper”. Expert Systems with Applications, 39(18): 3295-13304,(2012).

[29] Vatankhah, R., Broushaki, M., Alasty, A., "Adaptive optimal multi-critic based neuro-fuzzy control of MIMO human musculoskeletal arm model”. NeuroComputing, 173: 1529-1537, (2016).

[30] Topalov, A., Oniz, Y., Kayacan,E., Kayank, O., "Neuro-Fuzzy control of antilock braking system using sliding mode inceremental learning alogorithm",Neurocomputing, 74(11): 1883-1893,(2011).

[31] Liu, Y., Si-Yuan, L., Ning, W., "Fully-tuned fuzzy neural network based robust adaptive tracking control of unmanned underwater vehicle with thruster dynamics", Neuro Computing, 19(6): 1-13, (2016). 
[32] Sarhadi, P., Behrooz, R.., Zahra, R., "Adaptive predictive control based on adaptive neuro-fuzzy inference system for a class of nonlinear industrial processes" Journal of the Taiwan Institute of Chemical Engineers,132-137, (2015).

[33] Jia, Li., Kai, Yuan., "The probability density function based neuro-fuzzy model and its application in batch processes", Neurocomputing, 148: 216-221, (2015).

[34] Wang, W., De, Z. L., Joe, V., “An evolving neuro-fuzzy technique for system state forecasting”, Neurocomputing, 87:111-119, (2012).

[35] Petković, D., Pavlovic, N.T., Samshirband, S., Kiah, M.L.M., Anuar, N.B., Idris, M.Y.I., "Adaptive neuro-fuzzy estimation of optimal lens system parameters", Optical Laser Engineering, 55: 84-93, (2014).

[36] Hasanien, H., M., Muyeen S.,M., Junji, T., "Speed control of permanent magnet excitation transverse flux linear motor by using adaptive neuro-fuzzy controller", Energy Conversion Management, 51(12) :2762-2768, (2012).

[37] Premkumar, K., B. V. Manikandan., “Adaptive Neuro-Fuzzy Inference System based speed controller for brushless DC moto" Neuro Computing,138: 260-270, (2014).

[38] Premkumar, K., Manikandan B.V., "Fuzzy PID supervised online ANFIS based speed controller for brushless dc motor", Neuro Computing,157: 76-90, (2015).

[39] Reddy, K. H., Sudha, R., Prabhu, R., "Hybrid Adaptive Neuro Fuzzy based speed Controller for Brushless DC Motor". Gazi University Journal of Science, 30(1): 93-110, (2017).

[40] Ozturk, S., B., Hamid, A. Toliyat., "Direct torque and indirect flux control of brushless DC motor" IEEE/ASME Transactions on Mechatronics,16(2): 351-360, (2011).

[41] Pillay, P., Ramu, K., "Modeling, simulation, and analysis of permanent-magnet motor drives. I. The permanent-magnet synchronous motor drive", IEEE Transactions on Industry Applications,25(2): 265-273, (1989).

[42] Alphonse, I., Hosimin, T., F. Bright, S., "Design of solar powered BLDC motor driven electric vehicle", International Journal of Renewable Energy Research (IJRER), 2(3): 456-462, (2012).

[43] Rekioua, T., Rekioua D., "Direct torque control strategy of permanent magnet synchronous machines.” 2003 IEEE Bologna Power Tech Conference Proceedings, 2. IEEE, (2003).

[44] Tsotoulidis, S., N., Athanasios, N., S., "Analysis of a drive system in a fuel cell and battery powered electric vehicle" International Journal of Renewable Energy Research (IJRER), 1(3): 140-151,(2011).

[45] Benmouna, A., Becherif, M., Depernet, D., Depature, C., Boulon, L., "Nonlinear control and optimization of hybrid electrical vehicle under sources limitation constraints." International Journal of Hydrogen Energy 45(19): 11255-11266, (2020).

[46] Moshkbar-Bakhshayesh, K., Mohammad, B., G., "Development of an efficient identifier for nuclear power plant transients based on latest advances of error back-propagation learning algorithm", IEEE Transactions on Nuclear Science, 61(1): 602-610, (2014). 


\section{Annexure:}

\section{Training Data For ANFIS}

\begin{tabular}{|c|c|c|c|c|c|}
\hline Error & Change in Error & Output & Error & $\begin{array}{c}\text { Change in } \\
\text { Error }\end{array}$ & Output \\
\hline 1200 & 0 & 1003.34 & 32.85 & 731.14 & 115.03 \\
\hline 1200 & 0 & 1003.34 & 28.17 & -5806.14 & 112.36 \\
\hline 1200 & 0 & 1003.31 & 24.17 & -9601.01 & 110.18 \\
\hline 1200 & 0 & 1003.30 & 20.63 & 478.91 & 108.20 \\
\hline 1200 & 0 & 1003.26 & 17.76 & -4189.22 & 106.69 \\
\hline 1177.03 & -459262.35 & 985.89 & 15.12 & -6485.58 & 105.24 \\
\hline 1137.66 & -7.87393 .83 & 956.13 & 13.13 & 304.43 & 104.28 \\
\hline 1087.03 & -1012622.02 & 917.87 & 11.21 & -2214.92 & 103.24 \\
\hline 1021.84 & -1303851.99 & 868.61 & 9.93 & 1445.94 & 102.15 \\
\hline 961.43 & -1.208144 .40 & 822.97 & 8.56 & -169.47 & 101.62 \\
\hline 905.20 & -1124706.41 & 780.49 & 7.11 & 1397.58 & 100.92 \\
\hline 852.59 & -1052121.69 & 740.74 & 6.41 & 1374.57 & 100.08 \\
\hline 791.64 & -1219018.81 & 694.70 & 5.48 & 1057.71 & 99.91 \\
\hline 736.87 & -1095339.40 & 653.32 & 4.37 & 2551.54 & 99.48 \\
\hline 677.19 & -1193622.30 & 608.24 & 4.14 & 605.83 & 98.86 \\
\hline 624.63 & -1051222.06 & 568.54 & 3.57 & 3955.59 & 99.010 \\
\hline 569.39 & -1104819.03 & 526.81 & 2.75 & 453.97 & 98.83 \\
\hline 521.28 & -962119.89 & 490.47 & 2.94 & 5697.73 & 98.39 \\
\hline 471.95 & -986583.51 & 453.21 & 2.71 & 659.79 & 97.77 \\
\hline 429.29 & -853368.52 & 420.99 & 2.13 & 7796.14 & 98.12 \\
\hline 386.34 & -858968.93 & 388.55 & 1.30 & 1215.27 & 98.12 \\
\hline 349.35 & -739824.07 & 360.61 & 1.77 & -4623.27 & 97.83 \\
\hline 312.67 & -733472.08 & 332.91 & 1.76 & 6742.87 & 98.35 \\
\hline 281.17 & -629954.66 & 309.12 & 0.36 & -867.57 & 98.40 \\
\hline 250.36 & -616374.41 & 285.84 & 0.31 & -7210.99 & 98.13 \\
\hline 223.94 & -528349.47 & 265.89 & 0.10 & 8305.18 & 98.49 \\
\hline 198.40 & -510790.82 & 246.60 & 0.12 & -414.34 & 98.43 \\
\hline 176.54 & -437239.30 & 230.09 & 0.04 & -7436.63 & 98.09 \\
\hline 155.64 & -417917.73 & 214.31 & 0.05 & 11886.66 & 97.57 \\
\hline 136.09 & -391039.60 & 199.54 & 0.03 & 1838.56 & 97.60 \\
\hline 119.53 & -331149.48 & 187.04 & 0.026 & -6088.24 & 97.37 \\
\hline 104.14 & -307780.54 & 175.42 & 0.08 & -12075.99 & 96.99 \\
\hline 91.085 & -261228.45 & 165.55 & 0.07 & 13711.11 & 97.02 \\
\hline 79.05 & -240632.68 & 156.47 & 0.21 & 3260.23 & 96.85 \\
\hline 68.81 & -6009.5311 & 148.74 & 0.20 & 22181.58 & 96.60 \\
\hline 59.49 & 10007.6871 & 141.70 & 0.43 & 7617.90 & 96.81 \\
\hline 51.53 & -1024.97 & 135.68 & 0.82 & -3037.30 & 96.52 \\
\hline 44.38 & -8451.18 & 130.29 & 0.57 & 12664.70 & 96.59 \\
\hline
\end{tabular}

